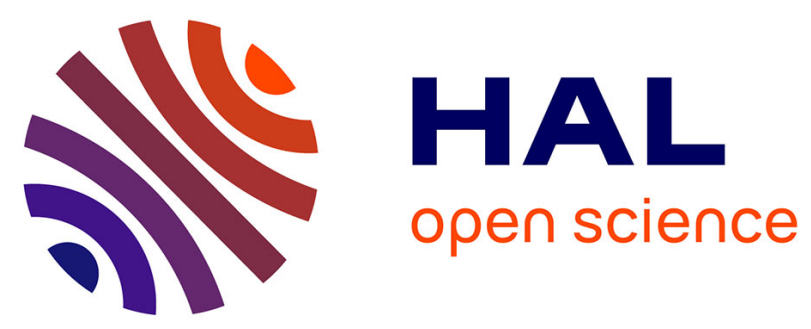

\title{
STEM-EELS investigation of c-Si/a-AlO interface for solar cell applications
}

\author{
Guillaume Noircler, Fabien Lebreton, Etienne Drahi, Patricia de Coux,
} Bénédicte Warot-Fonrose

\section{- To cite this version: \\ Guillaume Noircler, Fabien Lebreton, Etienne Drahi, Patricia de Coux, Bénédicte Warot-Fonrose. STEM-EELS investigation of c-Si/a-AlO interface for solar cell applications. Micron, 2021, 145, pp.103032. 10.1016/j.micron.2021.103032 . hal-03346456}

\section{HAL Id: hal-03346456 https://hal.science/hal-03346456}

Submitted on 11 Oct 2021

HAL is a multi-disciplinary open access archive for the deposit and dissemination of scientific research documents, whether they are published or not. The documents may come from teaching and research institutions in France or abroad, or from public or private research centers.
L'archive ouverte pluridisciplinaire HAL, est destinée au dépôt et à la diffusion de documents scientifiques de niveau recherche, publiés ou non, émanant des établissements d'enseignement et de recherche français ou étrangers, des laboratoires publics ou privés. 


\section{STEM-EELS investigation of c-Si/a-AlO ${ }_{x}$ interface for solar cell applications}

Guillaume NOIRCLER ${ }^{*, 1,2,3}$, Fabien LEBRETON ${ }^{1,3,4}$, Etienne DRAHI ${ }^{1,3}$, Patricia de COUX $^{1}$, and Bénédicte WAROT-FONROSE ${ }^{2}$

${ }^{1}$ Total S.A., 2 place Jean Millier, 92400 Paris La Défense, France

${ }^{2}$ CEMES-CNRS, Université de Toulouse, CNRS, 29 rue Jeanne Marvig, 31055

Toulouse, France

${ }^{3}$ Institut Photovoltaïque d'Ile-de-France (IPVF), 18, Boulevard Thomas

Gobert, 91120 Palaiseau France

${ }^{4}$ LPICM-CNRS - Ecole Polytechnique, 91128 PALAISEAU, France

${ }^{*}$ Corresponding author: guillaume.noircler@cemes.fr 


\section{Introduction}

Unlike the microelectronics field where Transmission Electron Microscopy (TEM) is extensively used in failure analysis, process development, and metrology [1], in the photovoltaic field TEM is rarely used because materials such as amorphous hydrogenated materials [2][3] or perovskite structures are very unstable under the electron beam, posing great challenges and requiring special care in establishing characterization methodologies. Local information provided by TEM techniques thanks to their high spatial resolution could provide a better understanding of physico-chemical mechanisms and therefore lead to improved manufacturing processes to have more efficient solar cells. The purpose of this article is therefore to report, detail and limit as far as possible the electron beam irradiation damage in order to have a characterization as relevant as possible. The aim of the article is to propose methods that can be used on standard microscope with no major instrumental modification. We propose a methodology to study amorphous aluminum oxide / amorphous hydrogenated silicon nitride (a- $\left.\mathrm{AlO}_{x} / \mathrm{a}-\mathrm{SiN}_{x}: \mathrm{H}\right)$ passivation stacks deposited respectively by Atomic Layer Deposition (ALD) and Plasma Enhanced Chemical Vapor Deposition (PECVD) on p-type crystalline silicon (c-Si). In c-Si solar cell, passivation layers are used to preserve the electronic properties by limiting the surface recombination. This dielectric passivation stack has allowed to move from the Al-BSF (Aluminium Back Surface Field) device to the PERC (Passivated Emitter and Rear Cell) device. Nowadays, a- $\mathrm{AlO}_{x} / \mathrm{a}-\mathrm{SiN}_{x}: \mathrm{H}$ is also a good candidate to passivate the rear side of two-terminal perovskite/silicon tandem cells [5]. The well known thermal oxidation $\left(\mathrm{a}-\mathrm{SiO}_{2}\right)$ of the c-Si surface carried out at temperature between 800 $1000^{\circ} \mathrm{C}$ is no longer accepted in terms of industrial thermal budget and therefore has to be avoided in order to decrease the cell process cost. Deposited at temperatures between $200^{\circ} \mathrm{C}$ and $300^{\circ} \mathrm{C}$, ultrathin a- $\mathrm{AlO}_{x}$ provides chemical passivation by reducing c-Si dangling bonds at the interface and offers a field effect passivation mainly through intrinsic negative fixed charges which drastically decrease the surface recombination velocity. The control of these negative fixed charges remains difficult because their origin is believed to be diverse (vacancies, interstitial atoms, coordination, traps) [6][7][8]. a- $\mathrm{SiN}_{x}: \mathrm{H}$ is an anti-reflective layer, as well as an hydrogen reservoir which improves the chemical passivation at the $\mathrm{c}-\mathrm{Si} / \mathrm{a}-\mathrm{AlO}_{x}$ interface. Moreover it acts also as a capping layer improving the thermal and chemical stability of a- $\mathrm{AlO}_{x}$. In this work, in order to understand the electron-beam sensitivity during Scanning 
TEM coupled with Electron Energy Loss Spectroscopy (STEM-EELS), we carry out a detailed electronbeam irradiation damage study of the c-Si/a- $\mathrm{AlO}_{x}$ interface. The importance of the electronic dose and the accelerating voltage in the formation of this damage will be argued. Useful information will be given to limit the dominant irradiation damage by modifying STEM-EELS acquisition parameters. Finally the composition of the interface will be analyzed thanks to these optimized analysis parameters and then discussed.

\section{Material and methods}

The passivation stack composed of $\mathrm{a}-\mathrm{AlO}_{x}$ and $\mathrm{a}-\mathrm{SiN}_{x}: \mathrm{H}$ was symmetrically deposited on a polished crystalline silicon (c-Si) test cell (also called lifetime samples) by Lebreton et al.[9]. Lifetime samples are intended for research and development purposes, the rear side of the studied solar cell architecture being processed on both sides of the wafer. The p-type (100) c-Si Float Zone (FZ) substrate was doubleside polished, with a resistivity of $3 \Omega . c m$ and a thickness of $280 \mu \mathrm{m}$. After dipping the latter into $5 \%$ $\mathrm{HF}, \mathrm{a}-\mathrm{AlO}_{x}$ deposition using Trimethylaluminum (TMA) and water was carried out by Thermal-Drift Atomic Layer Deposition (TD-ALD). For these samples, the thermal drift conditions mean that the deposition is carried out when the temperature of the substrate increases from $200^{\circ} \mathrm{C}$ to $250^{\circ} \mathrm{C}$ during 60 ALD cycles (corresponding to a layer of $6 \mathrm{~nm}$ ). This variation of the temperature during deposition enables the surface recombination velocities below $10 \mathrm{~cm} \cdot \mathrm{s}^{-1}$ (typical value required to have solar cells with a power conversion efficiency higher than $20 \%$ [10]) and prevents the formation of blisters (defects studied and characterized by Lebreton et al. [11]) that degrade the optical and electrical properties of such a passivation stack. The as-deposited a- $\mathrm{AlO}_{x}$ layer brings a chemical passivation of the c-Si surface, the advantage of a- $\mathrm{AlO}_{x}$ is that it also provides a field effect passivation which is activated by an annealing step in a forming gas atmosphere during 30 minutes at $380^{\circ}$. The a-SiN ${ }_{x}: \mathrm{H}$ capping of $75 \mathrm{~nm}$ is performed by Plasma Enhanced Chemical Vapor Deposition (PECVD) at $420^{\circ} \mathrm{C}$ and is followed by a final annealing step done at $380^{\circ} \mathrm{C}$ for 20 minutes which simulates an electroplating metallization step [12].

The structure of the interface in such stack needs to be characterized with a local investigation 
technique, transmission electron microscopy (TEM) has been chosen in this study to complete other macroscopic characterizations [11][13]. TEM requires specific sample preparation to get electron transparent lamella. Using Focused Ion Beam (FIB), these lamella were lifted out as cross sections through the epi-layer using an adaptation of the Schaffer et al. method [14]. A FEI Helios NanoLab 600i was used to perform the lift-out technique that allows to have the least damage of the sample and to have the best atomic resolution in STEM and HRTEM. The first step of the FIB preparation is the orientation of the sample to have the desired [110] zone axis to observe low index family planes edge on. Then, a platinum layer was deposited first by using the electron beam and then by using the ion beam. Indeed, electron beam induced deposition is less energetic than ion beam induced deposition and allows to preserve the sample surface. Initial wedge-milling was performed using a gradual decrease of gallium ions voltage from $30 \mathrm{kV}, 16 \mathrm{kV}, 8 \mathrm{kV}$ to $5 \mathrm{kV}$ with the cleaning cross section (CCS) pattern. Compared with the classic lift-out FIB pre-milling described by Bals et al.[15], which uses parallel pre-milling with a constant voltage at $30 \mathrm{kV}$, the wedge-milling that we used allows to preserve the area of interest against amorphization [16] and to limit gallium implantation by decreasing the tension at each milling step. The thinning was carried out in staircase profile, each voltage corresponding to a step of the stair ; this allows us to see the progress of the thinning. Once the $5 \mathrm{kV}$ of ion beam was reached, we used a $5 \mathrm{kV}$ electron beam during milling to monitor the thinning process. A contrast reversal allowed us to monitor the thickness of the lamella. The last thinning steps were done at $2 \mathrm{kV}$ and $1 \mathrm{kV}$ with Rectangular Cross Section pattern and the thickness monitoring with electron beam at $2 \mathrm{kV}$. This technique is much longer (around 4 hours) than the classical one but gives high quality and thin $(\leq 70 \mathrm{~nm})$ electron transparent area over $6 \mu \mathrm{m}$ length for STEM analysis. This method has been chosen because FZ silicon used as a substrate in this study is more likely to be contaminated than Czochralski silicon. Indeed, the increased purity of the material leads to a higher sensitivity to contamination. Thus, this is a real challenge both for preparation (ion beam) and for observation (electron beam and carbon contamination).

A JEOL ARM200F aberration corrected STEM with a probe size of $0,1 \mathrm{~nm}$ was used for chemical imaging and spectroscopy. The real probe size is however larger than this theoretical one due to the probe shape and some lateral extension within the thin lamella, especially throughout the amorphous 
layer. STEM-HAADF images were taken before and after STEM-EELS acquisition to check if there was any change in contrast or in the structure due to electron beam damage. Electron energy loss spectroscopy (EELS) was performed with a GIF Quantum ER detector in STEM mode, using a 30 mrad convergence and 39 mrad collection angle. Energy resolution was measured at the full width at half maximum of the zero loss peak (ZLP) to be between 0.4 and $0.5 \mathrm{eV}$ for all our experiments. A dispersion of $0.05 \mathrm{eV} / \mathrm{ch}$ was chosen to study the Energy Loss Near-edge fine Structures (ELNES) of $\mathrm{Al} \mathrm{L}_{2,3}$ and $\mathrm{Si} \mathrm{L}_{2,3}$ edges. This dispersion was chosen to track any modification of the silicon oxidation number that could be deduced from the modification of the $\mathrm{Si}_{2,3}$ edges ELNES signal. The a-AlO ${ }_{x}$ electron beam sensitivity forced us to study the $\mathrm{L}_{2,3}$-edges rather than the high energy K-edges of aluminium which would imply longer exposure times and consequently more damage to the interface and the passivation stack. The EELS spectra were recorded by using DualEELS and Spectrum Image (SI) acquisitions. DualEELS is a system directly implemented in the EELS spectrometer which allows the acquisition for each pixel of two energy loss spectra from different energy ranges. We used it in two different ways, either by recording ZLP and plasmon peaks on the first energy range and Al $\mathrm{L}_{2,3}$-edge and $\mathrm{Si} \mathrm{L}_{2,3}$-edge on the second range to deconvolve spectra or by recording $\mathrm{Al} \mathrm{L}_{2,3}$-edge and $\mathrm{Si} \mathrm{L}_{2,3}$-edge on the first range and the $\mathrm{O} \mathrm{K}$-edge on the second range to study the evolution of the fine structures of these edges which are more than $400 \mathrm{eV}$ apart (as presented in Figure 3). Spectrum image [17] is a 3D data set i.e at each x-y position (navigation space) which forms a pixel of the image an entire spectrum is stored along the $\mathrm{z}$ axis (signal space) e.g., if we sum over several pixels in a area containing one material (like silicon) it will increase the signal-to-noise ratio providing better definition of the considered ELNES. During data treatment, Principal Component Analysis (PCA) was applied to extract the main components of our SI which were hidden by noise using the temDM MSA software routine for DigitalMicrograph available at www.temdm.com. Indeed, PCA is a well known multivariate statistical analysis allowing the isolation of meaningful variations from noise. The profiles and maps displayed on Figure 2 and Figure 3 were obtained thanks to a processing tool included in DigitalMicrograph called Multiple Linear Least-Squares (MLLS) fitting [18]. The latter routine aims at decomposing the considered spectrum as a linear sum of theoretical or experimental reference spectra. As the shape of the c-Si and a-AlO ${ }_{x}$ ELNES of our EELS measurements had the 
same characteristics as the literature references, we have directly taken the references in our data. Furthermore, MLLS fitting bring better results when the reference data are recorded with the same acquisition conditions as those applied to the studied materials.

\section{Results}

As explained before, the goal of this article is to analyze the c-Si/a- $\mathrm{AlO}_{x}$ interface from a passivation stack a- $\mathrm{AlO}_{x} /$ a-SiN $x$ :H over c-Si which is highly sensitive to the electron beam. Previous High Resolution TEM (HRTEM) experiments (not shown here) indicated a high sensitivity of a- $\mathrm{AlO}_{x}$ and a-SiN $x: \mathrm{H}$ layers. Indeed, a- $\mathrm{AlO}_{x}$ can crystallize into $\gamma-\mathrm{Al}_{2} \mathrm{O}_{3}$ under the electron beam, as determined by many authors [2][3][19] and a-SiN $\mathrm{Si}_{x}: \mathrm{H}$ can undergo huge morphological modifications with the formation of bubble-like defects as reported by Liu et al. [20]. It was thus very difficult to have faithful HRTEM images of the stack and the c-Si/a- $\mathrm{AlO}_{x}$ interface, even by limiting the electron dose. However, we can see in Figure 1.a) that the $\mathrm{a}-\mathrm{SiN}_{x}: \mathrm{H}$ and the $\mathrm{a}-\mathrm{AlO}_{x} / \mathrm{a}-\mathrm{SiN}_{x}: \mathrm{H}$ interfaces are very sensitive even when using STEM. Indeed, in this image acquired at $200 \mathrm{keV}$, some parts of the a-SiN $\mathrm{S}_{x} \mathrm{H}$ bulk started to be extensively damaged and it also started to loose its adhesion with a- $\mathrm{AlO}_{x}$ under the beam while $\mathrm{c}-\mathrm{Si} / \mathrm{a}-\mathrm{AlO}_{x}$ interface and $\mathrm{a}-\mathrm{AlO}_{x}$ remained intact. That is the reason why, we took this image as a reference to measure c-Si/a- $\mathrm{AlO}_{x}$ interface and $\mathrm{a}-\mathrm{AlO}_{x}$ thickness. 


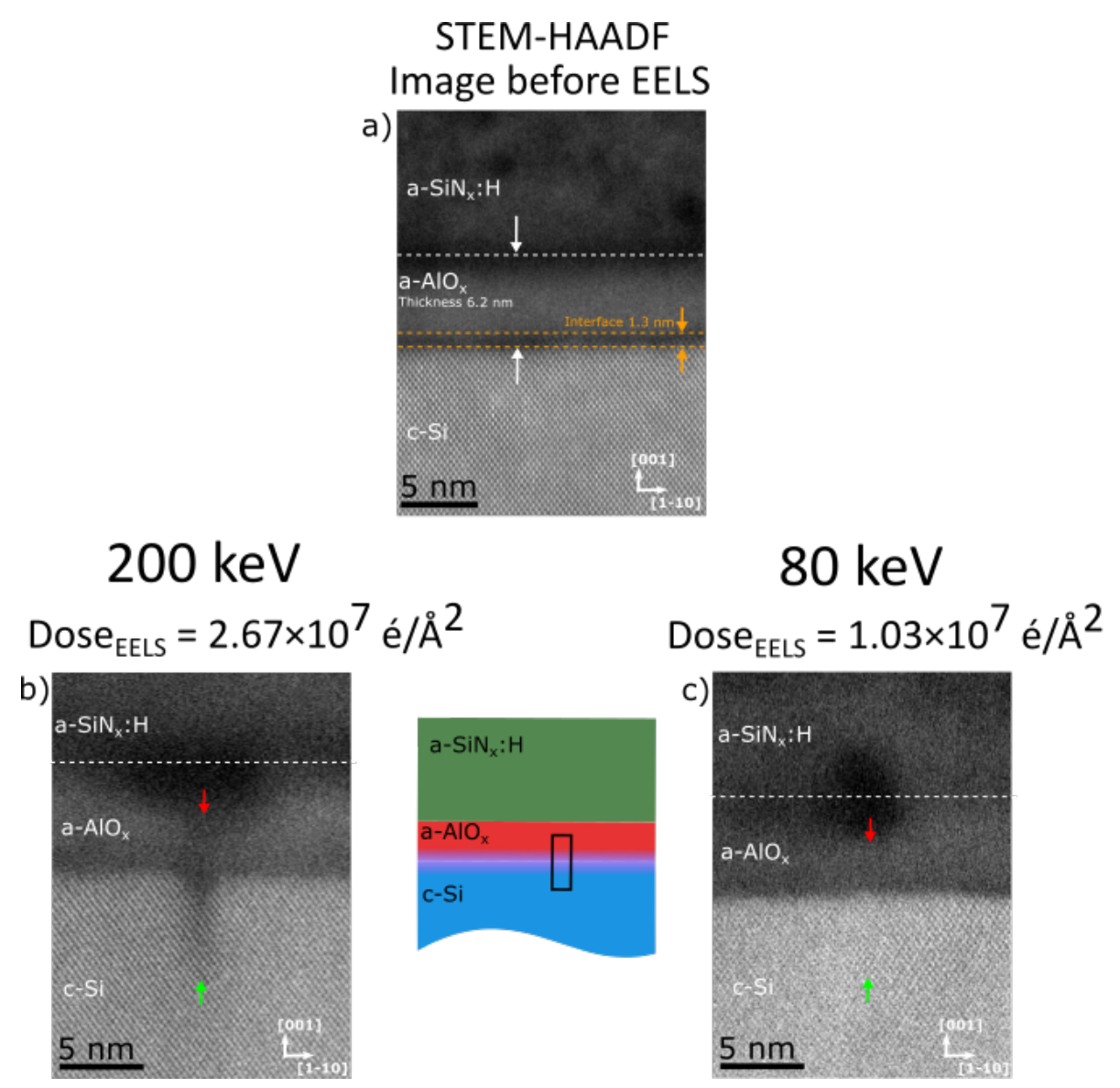

Figure 1: STEM-HAADF images before and after EELS Spectrum Image recording. a) STEMHAADF before EELS. b) STEM-HAADF after STEM-EELS at 200keV. c) STEM-HAADF image after STEM-EELS at $80 \mathrm{keV}$.

From the latter image (Figure 1.a)) the thickness of a- $\mathrm{AlO}_{x}$ was measured to be $6.2 \mathrm{~nm}$ as expected from the deposition process. We were also able to measure an interfacial layer contrast of $1.3 \mathrm{~nm}$ at the c-Si/a- $\mathrm{AlO}_{x}$ interface meaning that there is the formation of another chemical compound between c-Si and a- $\mathrm{AlO}_{x}$. STEM-EELS studies were carried out to explain this contrast and the acquisition parameters of the spectra had to be adjusted to take the beam sensitivity into account. We started STEM-EELS experiments at an acceleration voltage of $200 \mathrm{keV}$, spectra were acquired in the black box area represented in the drawing of Figure 1 thanks to the EELS SI technique (as described in experimental part). The acquisition begins in c-Si (at the tip of the green arrow in Figure 1.b) and 
Figure 1.c)) and ends in the middle of the a- $\mathrm{AlO}_{x}$ layer(at the tip of the red arrow in Figure 1.b) and Figure 1.c) ). Figure 1.b) shows a STEM-HAADF image recorded after STEM-EELS SI, the electron beam leaves huge degradation marks which begin in the c-Si and the degradation becomes more important closer to the interface. From a structural point of view, we can observe a loss of crystallinity near the interface in the c-Si: some crystal planes are missing. Furthermore, HAADF contrast over the entire degraded area is much darker than c-Si HAADF contrast, which indicates that in addition to the loss of crystallinity, there is also the formation of chemical compound other than silicon. Thus, to overcome this damage, we decided to decrease the accelerating voltage keeping constant all other parameters (condenser aperture, spot size, exposure time, pixel size) which leads to a decrease in the probe current and therefore in the electronic dose received by the sample. The STEM-HAADF image in Figure 1.c) displays a clear improvement, the crystal structure of silicon is preserved and there is no visible change in contrast. All the EELS experiments which are presented in the rest of this article were carried out with the same dose of $1.03 \times 10^{7} \mathrm{e} / \AA^{2}$. The electron dose for our EELS experiments is given by:

$$
D_{E E L S}=\frac{i \times t}{e \times S}
$$

in which $e$ is the electron charge in Coulomb $(\mathrm{C}), i(\mathrm{C} / \mathrm{s})$ is the current given by the manufacturer as a function of spot size and condenser aperture, $t$ is the exposure time, and $S$ represents the pixel area in $\AA^{2}$. Note that the a-SiN $x: \mathrm{H}$ layer and therefore the a- $\mathrm{AlO}_{x} / \mathrm{a}-\mathrm{SiN}_{x}: \mathrm{H}$ interface already very sensitive to STEM-HAADF imaging, as mentioned above, are all the more sensitive in STEM-EELS. We therefore focused only onto the $\mathrm{c}-\mathrm{Si} / \mathrm{a}-\mathrm{AlO}_{x}$ interface 


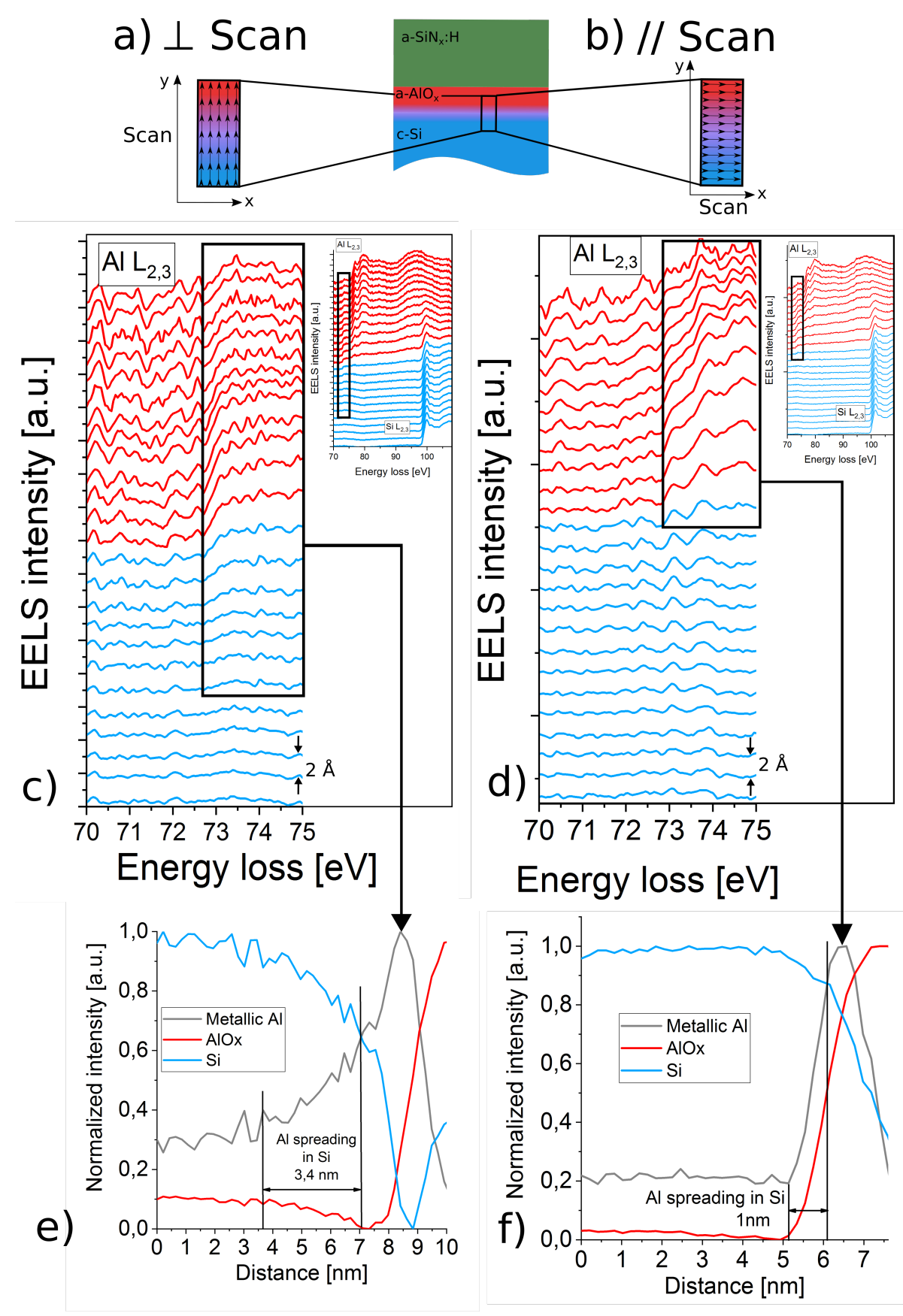

Figure 2: Comparison of EELS spectrum image recording of two scanning methods at $80 \mathrm{keV}$. a) and b) are drawing representation of STEM-EELS perpendicular $(\perp$, scan along the y axis) and parallel (//, scan along the $\mathrm{x}$ axis) scanning over the c-Si/a-AlO $\mathrm{Al}_{x}$ interface respectively. c) and d) are EELS spectrum corresponding to $\perp$ scan and //scan respectively showing Al- $\mathrm{L}_{2,3}$-edge with their inset showing the entire dispersion of the EELS experiments with $\mathrm{AlL}_{2,3}$-edge and $\mathrm{SiL}_{2,3}$-edge. e) and f) are MLLS profile of STEM-EELS $\perp$ scan and //scan respectively. 
Besides the dose control, another acquisition parameter has been studied. We have indeed compared two spectrum image recording techniques on the same sample (same FIB lamella). The first one will be referred as " $\perp$ scan" because the electron beam passes perpendicularly to the c-Si/a- $\mathrm{AlO}_{x}$ interface along the y axis for recording EELS spectrum as depicted by the black arrows in Figure 2.a). The second one, referred as "//scan" because the electron beam approaches, scans and records along a line parallel to the interface along the $\mathrm{x}$ axis as illustrated in Figure 2.b). Spectrum c) and d) of Figure 2 and their insets are the result of EELS spectrum image of $1 \mathrm{~nm} \times 10 \mathrm{~nm}$ with a pixel size of $0.2 \mathrm{~nm} \times$ $0.2 \mathrm{~nm}$ and a pixel time of $0.1 \mathrm{~s}$. For both $\perp$ scan and $/ /$ scan, spectra were summed along the $\mathrm{x}$ axis for data treatment. Spectrum c) and d) display only the beginning of energy-loss near-edge structure (ELNES) of $\mathrm{Al} \mathrm{L}_{2,3}$-edge to focus on it while their insets show the full range of our EELS experiments containing the full $\mathrm{Al} \mathrm{L}_{2,3}$-edge and the ELNES of the $\mathrm{Si}_{2,3}$-edge. The edge onset characteristic of $\mathrm{Al}$ $\mathrm{L}_{2,3}$-edge of metallic $\mathrm{Al}$ is at $73 \mathrm{eV}$ and it arises by a net shouldering, observed in c) and d) spectrum of Figure 2. The c) and d) insets in Figure 2 allow, on the one hand, to identify the shouldering of metallic $\mathrm{Al}$ on the whole energy range chosen for our EELS experiments and on the other hand to understand how and where $\mathrm{a}-\mathrm{AlO}_{x}$ begins with respect to c-Si in the stacked EELS spectra. Indeed, the shape of $\mathrm{Al} \mathrm{L}_{2,3}$-edge is modified for a- $\mathrm{AlO}_{x}$ which is characterized by one peak at $78 \mathrm{eV}$ and another broad peak at $80 \mathrm{eV}$. For the c-Si, the $\mathrm{Si} \mathrm{L}_{2,3}$-edge is located at $99 \mathrm{eV}$. Thus, the blue spectra corresponds to the c-Si and the red spectra corresponds to a- $\mathrm{AlO}_{x}$ which begins when the $78 \mathrm{eV}$ peak starts to appear. The position and shape of these characteristic edge will be analyzed in more detail in the next paragraph in order to determine the local coordination. On spectra c) and d) from Figure 2, we can observe that the presence of metallic $\mathrm{Al}$ varies according to the recording technique used. The metallic $\mathrm{Al}$ is located in a- $\mathrm{AlO}_{x}$ and spreads over the c-Si for the $\perp$ scan whereas it is located only in a- $\mathrm{AlO}_{x}$ for the $/ /$ scan. This shows that the presence of metallic $\mathrm{Al}$ might be due to and/or enhanced by an interaction between the electron beam and the structure (more details about this interaction in the Discussion part). Interestingly this interaction can be limited by using the //scan. The semiquantitative MLLS profiles (explained in the experimental part) e) and f) in Figure 2 allows to show significantly the metallic $\mathrm{Al}$ spreading over $\mathrm{c}-\mathrm{Si}$ and $\mathrm{a}-\mathrm{AlO}_{x}$ with better precision than using only EELS spectra. Thus, by using //scan, it reduces the metallic $\mathrm{Al}$ spreading in c-Si by a factor of 3 . 
The following experiments were therefore carried out by //scan.
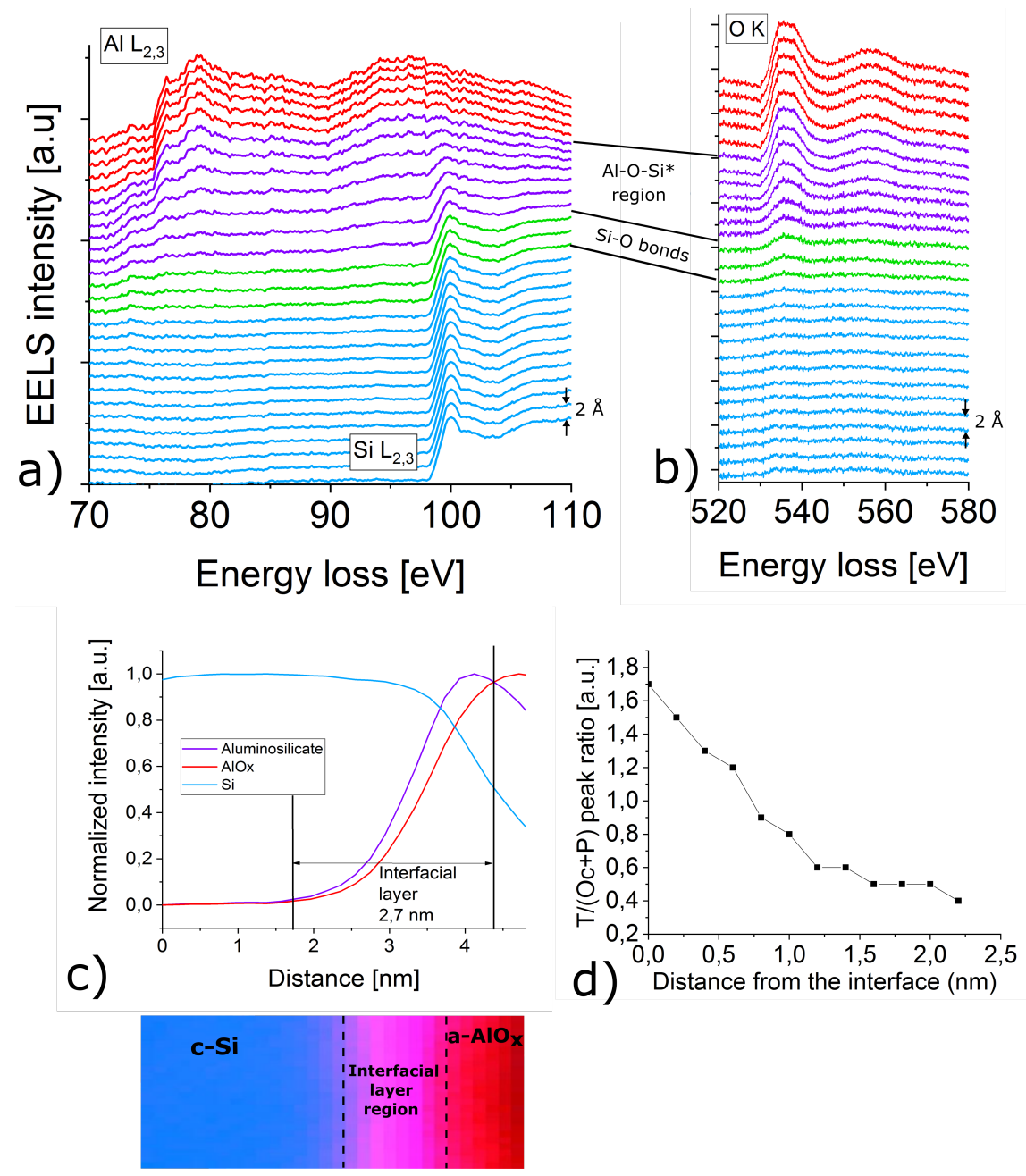

Figure 3: STEM-EELS experiment recorded at $80 \mathrm{keV}$. a) EELS spectrum showing $\mathrm{Al}$ and $\mathrm{Si} L_{2,3^{-}}$ edge of c-Si/a-AlO ${ }_{x}$. b) EELS spectrum showing O K-edge of c-Si/a-AlO ${ }_{x}$. Those two spectrum allow to highlight that the c-Si/a- $\mathrm{AlO}_{x}$ interface is composed of aluminum silicates (purple spectrum) and Si-O bonds (green spectrum) at the interface. c) MLLS profile and map showing the interfacial layer. d) $\mathrm{T} /(\mathrm{Oc}+\mathrm{P})$ ratio as a function of the distance to the $\mathrm{c}-\mathrm{Si} / \mathrm{a}-\mathrm{AlO}_{x}$ interface showing high proportion of tetrahedrally coordinated $\mathrm{Al}$ in the first layer of aluminum silicate.

After having demonstrated that metallic $\mathrm{Al}$ can be enhanced by the electron beam and that therefore it could be an artifact, we can now analyze the c-Si/a- $\mathrm{AlO}_{x}$ interface with more caution. The EELS spectrometer we used has the DualEELS function which allows to acquire two different energy 
regions of the EELS signal simultaneously with exactly the same parameters. This is typically what is shown in Figure 3: a) represents the lower energy region with the $\mathrm{Al} \mathrm{L}_{2,3}$-edge and the $\mathrm{Si} \mathrm{L}_{2,3}$-edge while b) represents the higher energy with $\mathrm{O}$ K-edge. Thus, a spectrum in the lower energy region is associated with a spectrum in the higher energy region.

Let us describe the lower part: as already said, characteristic ELNES of a- $\mathrm{AlO}_{x}$ are one peak at $78 \mathrm{eV}$ and another broad peak at $80 \mathrm{eV}$, indeed for $\mathrm{Al}_{2} \mathrm{O}_{3}$ compounds this region is related to the studied phase (amorphous, $\gamma, \alpha, \beta, \theta$ ) and should depend on the coordination [21], these two peaks are even often associated respectively with tetrahedral and octahedral coordination [22][23]. However, it has been demonstrated experimentally by NMR [24][25] as well as by simulation [26] that three coordinations can exist in $\mathrm{a}-\mathrm{AlO}_{x}$ that are tetrahedral $(\mathrm{T})$, pentahedral $(\mathrm{P})$ and octahedral $(\mathrm{Oc})$ and that their proportion depends on the process conditions and deposition technique used [27]. There are therefore 2 peaks for 3 coordinations. In EELS, the first peak at $78 \mathrm{eV}$ would correspond to the tetrahedral coordination [21] while the second one at $80 \mathrm{eV}$ would rather correspond to a mixture of pentahedral and octahedral coordination. In our case, the peak at $78 \mathrm{eV}$ is the first EELS characteristic that appears. We can therefore say, that tetrahedral coordination predominates in the first layers of a- $-\mathrm{AlO}_{x}$. To show that, we plot the $\mathrm{T} /(\mathrm{Oc}+\mathrm{P})$ ratio that is very high at the first layer of a- $\mathrm{AlO}_{x}$ Figure 3.d). Concerning the ELNES of the $\mathrm{Si}_{2,3}$-edge, its shape did not change along its thickness, but its intensity gradually decreases to give way to a- $\mathrm{AlO}_{x}$. There is however an area where the characteristics ELNES of c-Si and $\mathrm{a}^{-\mathrm{AlO}_{x}}$ coexist (colored in purple in Figure 3.a)).

The O K-edge in Figure 3.b) provides more information about this interfacial region. We can observe that $\mathrm{O}$ K-edge starts before the $\mathrm{Al} \mathrm{L}_{2,3}$-edge of $\mathrm{a}-\mathrm{AlO}_{x}$ i.e. that there is an area where $\mathrm{O} \mathrm{K}$ edge and $\mathrm{Si}_{2,3}$-edge coexist (green region in Figure 3.a) and b)). This informs us that there is probably some chemical bond between $\mathrm{Si}$ and $\mathrm{O}$. In the purple area of Figure 3.a) and b), the three edges of $\mathrm{Al}, \mathrm{Si}$ and $\mathrm{O}$ are present simultaneously, which would mean that there is aluminum silicates formation (Al-O-Si bonds) at the interface. And if we combine information from Figure 3.a) and d) we can see that tetrahedrally coordinated $\mathrm{Al}$ are contained in the aluminum silicate region. To highlight and quantify the composition in this region, a MLLS map and profile were done in Figure 3.c). Figure 3.c) shows an MLLS profile and map in which we have added an extrapolation of the aluminum silicate to 
define the c-Si/a-AlO ${ }_{x}$ interface. Indeed, as there is an area where a- $\mathrm{AlO}_{x}$ and c-Si coexist (the purple area), we multiplied the c-Si MLLS data by the a- $\mathrm{AlO}_{x}$ MLLS data, these are the purple region on the MLLS map and the purple curve on the MLLS profile. The interfacial region composed mainly of aluminum silicate extends over $2.7 \mathrm{~nm}$ which is approximately 2 times larger than the interfacial region measured on the STEM-HAADF image (Figure 1.a)). Indeed, MLLS profile taking into account EELS data, is more precise than the STEM-HAADF contrast intensity in the image.

\section{Discussion}

Figure 1 and Figure 2 tend to prove that our sample has undergone several electron radiation damages

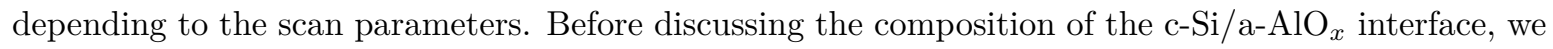
will try to identify what kind of electron damage takes place in our specimen. It should first be noted that electron radiation damage can be caused either by elastic (electron-nucleus interactions) or inelastic (electron-electron interactions) electron scattering which can be of different types [28][29]. Whether the degradation is due to elastic or inelastic scattering, it can cause microstructure modification of the targeted materials creating rearrangement or breaking unstable bonds.

Elastic electron scattering damages include sputtering and knock-on damages. Sputtering corresponds to surface atom displacement and/or ejection in the TEM column. It depends on the incident energy threshold ( $E_{0}$, also called accelerating voltage) which depends also on the analyzed elements. As reported by Egerton et al. in [28], light and medium-Z elements like $\mathrm{Si}, \mathrm{Al}, \mathrm{O}$ and $\mathrm{N}$ present in the studied samples are removed by sputtering.

Knock-on damages also concern atomic displacement due to $E_{0}$ but in the material volume. Each element has a displacement energy threshold $E_{d}$ in a considered material which can be determined experimentally or by simulations. This energy depends on the structure and so depends on the crystallography, that's why, e.g. for $\mathrm{Si}, E_{d}$ can take different values between 13-37 eV depending on the crystal family plane considered [30][31][32]. Thus, we can determine if the c-Si has suffered from knock-on 
damage by calculating the maximum knock-on energy transfer $\left(E_{\max }\right)[20][33]$ :

$$
E_{\max }=\frac{4 M_{e} M_{a} E_{0}}{\left(M_{e}+M_{a}\right)^{2}}
$$

, where $M_{e}$ is the mass of the incident electron and $M_{a}$ is the mass of the target atom in the material. The corresponding $E_{\max }$ in Si for $E_{0}=200 \mathrm{keV}$ and $E_{0}=80 \mathrm{keV}$ are respectively $15.6 \mathrm{eV}$ and $6.25 \mathrm{eV}$. Considering the $E_{d}$ of $\mathrm{Si}$, knock-on electron damage can occur at $E_{0}=200 \mathrm{keV}$. In the literature $E_{d}$ for $\mathrm{O}$ and $\mathrm{Al}$ have been determined only for crystalline or polycrystalline $\mathrm{Al}_{2} \mathrm{O}_{3}$ [3][34][35] and as Cooper et al. [36] demonstrated, it is too complex to predict $E_{d}$ for amorphous materials knowing $E_{d}$ for crystalline materials because it depends on too many parameters (bond energy, elastic strain energy, average mixing distance...). However, the $E_{d}$ values of amorphous materials are generally lower than crystalline materials. Taking into account the $E_{d}$ values of $\alpha-\mathrm{Al}_{2} \mathrm{O}_{3}$, Nakamura et al. [3] determined that knock-on was ubiquitous for $E_{0} \geq 300 \mathrm{keV}$, therefore $E_{0}$ for a- $\mathrm{AlO}_{x}$ will necessarily be below 300 $\mathrm{keV}$.

To avoid these two kind of electron damages, it is therefore necessary as recommended by Egerton [37] to work below the incident energy threshold $E_{0}$ by reducing the acceleration voltage when possible. Thus, concerning knock-on damage, decreasing the accelerating voltage from $200 \mathrm{keV}$ to $80 \mathrm{keV}$ allows to stop knock-on in c-Si and probably in a- $\mathrm{AlO}_{x}$. However, to stop sputtering damage, an acceleration voltage below $50 \mathrm{keV}$ should be used which is not convenient with most of TEM. Another way to limit sputtering and knock-on damage is to reduce the electron dose which has been achieved as explained before. At this stage, elastic radiation damage does not seem to be the dominant source of degradation.

Radiation damage from inelastic scattering can also be of two types: electron beam heating or ionization damage (known as radiolysis).

Murray et al. [2] reported that the crystallization of a- $\mathrm{AlO}_{x}$ into $\gamma-\mathrm{Al}_{2} \mathrm{O}_{3}$ was due to thermal process during electron irradiation. It should however be pointed out that a thin film of a- $\mathrm{AlO}_{x}$ started to crystallize at $1073 \mathrm{~K}$ [38]. Then, Nakamura et al. [3], demonstrated by the calculation and experimentally that crystallization cannot happen only by a thermal process because the elevation of the temperature during TEM analysis did not exceed $6 \mathrm{~K}$. As far as we are concerned, we observed metallic Al mobility after STEM-EELS experiments (Figure 2) instead of crystallization. However, a 
sole heat treatment could not induce the transformation of $\mathrm{a}-\mathrm{AlO}_{x}$ into metallic Al. Thus, in our case, we consider that heating induced by electron beam can be negligible.

Furthermore, the evolution of the thermodynamically stable $\alpha-\mathrm{Al}_{2} \mathrm{O}_{3}$ towards metallic $\mathrm{Al}$ under electron irradiation was intensively reported [21][39][40][41] and associated with ionization mechanism. Berger et al. [42] also characterized metallic thin surface film of Al after STEM hole drilling at $100 \mathrm{keV}$ of $\mathrm{Na} \beta-\mathrm{Al}_{2} \mathrm{O}_{3}$. Some authors [43][44] have exactly the same EELS characteristic of metallic $\mathrm{Al}$ (shouldering of $\mathrm{Al} \mathrm{L}_{2,3}$-edge at $73 \mathrm{eV}$ ) in a- $\mathrm{AlO}_{x}\left(\mathrm{Al} \mathrm{L}_{2,3}\right.$-edge forming one peak at $78 \mathrm{eV}$ and another broad peak at $80 \mathrm{eV}$ ) but the EELS characteristic of $\mathrm{Al}$ was expected since they were studying $\mathrm{Al} / \mathrm{a}-\mathrm{AlO}_{x}$ interface while in our case no metallic $\mathrm{Al}$ was expected in the original stack. Indeed, the presence of metallic $\mathrm{Al}$ at the $\mathrm{c}-\mathrm{Si} / \mathrm{a}-\mathrm{AlO}_{x}$ interface due to the manufacturing process was not often observed but it has been reported and characterized by NMR for an a- $\mathrm{AlO}_{x}$ deposited by metalorganic chemical vapor deposition (with different precursors than ours) at $480^{\circ} \mathrm{C}[45]$. As shown in Figure 2, the shouldering at $73 \mathrm{eV}$ in the EELS SI is characteristic of $\mathrm{Al}$ metal and the EELS SI (not shown here) corresponding to the STEM-EELS acquisition at $200 \mathrm{keV}$ of Figure 1.b) showed an enhancement of the metallic Al. So, a decrease of the acceleration voltage (causing a decrease of the electron dose) and a changing in scan direction acquisition from $\perp$ scan to //scan (Figure 2) can modify the metallic $\mathrm{Al}$ spreading at the c-Si/a-AlO $x$ interface. Taking into account those facts, we would suggest two hypothesis:

i) metallic $\mathrm{Al}$ is formed during manufacturing process or by contamination during the process

ii) metallic $\mathrm{Al}$ is due to electron beam irradiation.

Concerning hypothesis i), the presence of metallic Al due to manufacturing process would create positively charged defect sites in a- $\mathrm{AlO}_{x}$ which would lower the field effect passivation. This characterization shows us that the manufacturing process might be modified in order to find a way to remove the metallic Al. We will come back to this point in the last paragraph which deals with the composition of the interface. In the case of hypothesis ii) we believe that the formation of this metallic $\mathrm{Al}$ corresponds to a radiolysis process of $\mathrm{a}-\mathrm{AlO}_{x}$. This process has been described by Knotek-Feibelman [46] as an interatomic Auger process which implies a loss of three electrons from Oxygen $\left(\mathrm{O}^{2-}\right.$ to $\mathrm{O}^{+}$). Oxygen in the $\mathrm{O}^{+}$configuration is forced to desorb from the surface or to move to an interstitial 
position in the lattice. The aluminium ions are left as a metallic plug at the surface in the direction of the electron beam scan. However, it can be seen that only part of the Al-O bonds has undergone the radiolysis process since the fine structures of $\mathrm{a}-\mathrm{AlO}_{x}$ and $\mathrm{Al}$ coexist on several spectrum. In amorphous matrix, it has been reported that mainly the thermodynamically less stable bonds are likely to be broken or reorganized by electron excitation process like ionization [47]. It is known that a- $\mathrm{AlO}_{x}$ is composed of $\mathrm{AlO}_{4}, \mathrm{AlO}_{5}, \mathrm{AlO}_{6}$ basic units. The $\mathrm{AlO}_{5}$ unit is known to be the less stable, it is in particular involved in the crystallization process of a- $\mathrm{AlO}_{x}$ into $\gamma-\mathrm{Al}_{2} \mathrm{O}_{3}$ [3]. Therefore, this unstable unit could preferentially undergo the radiolysis process. Assuming the radiolysis is the main process involved in the $\mathrm{Al}$ metallic formation, it is known that increasing the acceleration voltage could reduce these damages. $[26,35,46]$. In our experiments, we have combined several parameters to control this radiolysis process: acceleration voltage, dose, scan orientation. A parallel scan orientation combined with a decrease of the acceleration voltage from $200 \mathrm{kV}$ to $80 \mathrm{kV}$, and hence a decrease of the electron dose, could prevent the $\mathrm{Al}$ spreading. This seems contradictory with the decrease of radiolysis damages when the acceleration voltage is increased but the influence of the dose seems predominant in our case [28][37][48]. In our experiments, we have chosen to decrease the acceleration voltage in order to decrease the electron dose and also because Hoex et al. [23] reported interesting EELS results at the c-Si/a- $\mathrm{AlO}_{x}$ working at $80 \mathrm{keV}$ but it would also be interesting to try other experiments at $200 \mathrm{keV}$ by reducing the dose by modifying e.g. the spot size or the condenser aperture.

Regarding the scan orientation, what could explain the reduction of the radiolysis process from $\perp$ scan to //scan. First of all, once the metallic $\mathrm{Al}$ is formed (or is already present at the interface), the driving force which allows its spreading is electrostatic [42]. Thus during the first $\perp$ scan SI, the electron beam has crossed c-Si and a- $\mathrm{AlO}_{x}$ where metallic $\mathrm{Al}$ started to spread. At the end of the first $\perp$ scan SI, the electron beam returns in c-Si (to start its second scan) where the metallic $\mathrm{Al}$ species created before are attracted and/or dragged by electrostatic driving force spreading metallic $\mathrm{Al}$ in c-Si. This mechanism cannot occur by using the //scan since the electron probe stayed in the c-Si during its first scans. In order to stop the radiolysis process, it would be interesting to use a cryo sample-holder which would drastically reduce the electron beam interactions and/or using a TEM equipped with an electron direct detection camera which allows to work with ultra low electron doses. 
As explained before, the particularity of a- $\mathrm{AlO}_{x}$ is that it provides both chemical and especially field effect passivation by a large contribution of negative charges near the interface. In the following part, we will discuss how the composition c-Si/a-AlO ${ }_{x}$ can influence the c-Si passivation. Figure 3 allows to determine that some Si-O bonds are present at the interface for a thickness of approximately $0.5 \mathrm{~nm}$ but we cannot give the exact oxidation number of silicon since the shape of the $\mathrm{Si}_{2,3}$-edge is not modified. Indeed, if the oxidation number of silicon was $\mathrm{Si}^{4+}$, two peaks at 106 and $108 \mathrm{eV}$ would have been present on the EELS spectra. It is difficult to track down other oxidation signatures of silicon in silicon oxide $\left(\mathrm{a}-\mathrm{SiO}_{x}\right)$ with EELS, only Batson [49] reported that $\mathrm{Si}^{2+}$ gives way to a broad and weak peak at $103 \mathrm{eV}$. Thus, in the $0.5 \mathrm{~nm}$ thick interfacial a-SiO${ }_{x}$, the oxidation number of $\mathrm{Si}$ can be $\mathrm{Si}^{1+}, \mathrm{Si}^{2+}, \mathrm{Si}^{3+}$. The thin a- $\mathrm{SiO}_{x}$ is therefore oxygen deficient which promotes the presence of oxygen vacancies that would tend to be positively charged [50][51]. Nevertheless, those positive charges at the interface could be compensated by the excess of hydrogen intrinsically present in the a- $\mathrm{AlO}_{x}$ or $\mathrm{H}$ diffusing from the $\mathrm{a}-\mathrm{SiN}_{x}: \mathrm{H}$ through the ultrathin $\mathrm{a}-\mathrm{AlO}_{x}$ to the c-Si/a-AlO $\mathrm{Ant}_{x}$ interface where it passivates the dangling bonds of the c-Si and could probably form $\mathrm{Al}-\mathrm{H}$ pairs in a- $\mathrm{AlO}_{x}$ which would enhance the field effect passivation as those pairs have a charge state of -1 [26]. Note that hydrogen bonds cannot be characterized with EELS. Whatever the structure or the stoichiometry of a- $\mathrm{SiO}_{x}$, the basic building block remains tetrahedral[52][53][54]. This tetrahedral coordination influences the coordination of $a-\mathrm{AlO}_{x}$ on its first layers which is also tetrahedral [21][22][23][55] as we have been able to characterize at the beginning of the purple region by the predominance of the $78 \mathrm{eV}$ peak in Figure 3. Bonding between $\left(\mathrm{SiO}_{4}\right)^{4-}$ and $\left(\mathrm{AlO}_{4}\right)^{5-}$ basic units produces a net negative charge [56][57] thus improving the field effect passivation.

On top of the c-Si surface, there is a mix between $\mathrm{a}-\mathrm{AlO}_{x}$ and $\mathrm{a}-\mathrm{SiO}_{x}$ that forms an aluminum silicate framework Figure 3. As the passivation stack has undergone several annealings at relatively low temperature, we would rather be in the presence of a non-stoichiometric aluminum silicate (Al-O-Si*) [58]. This is coherent with non-stoichiometric $\mathrm{a}-\mathrm{SiO}_{x}$ found at the interface. The metallic Al that we found at the interface would be an evidence that the formation of the aluminum silicate occurs through the reaction of $\mathrm{Al}, \mathrm{O}_{2}$ and $\mathrm{Si}$, and therefore that oxidation at the interface is only partial. As we said above, the metallic $\mathrm{Al}$ site could contribute to a decrease in the performance of the device by adding 
positive charges in the a- $\mathrm{AlO}_{x}$.

In addition, in this kind of passivation stack, it has been shown by a light induced field effect enhancement study that most of the negative fixed charges are in fact trapped charges and the best candidates for charge trapping in $\mathrm{a}-\mathrm{AlO}_{x}$ are reported to be interstitial oxygen sites [59][60]. It is also reported that tetrahedrally coordinated $\mathrm{Al}$ specifically contained in amorphous aluminum silicates have a very strong catalytic activity [55][61][62] and could enhance the field effect passivation [60]. This last point is consistent with our results (tetrahedrally coordinated $\mathrm{Al}$ in aluminum silicate) and could lead to other investigations.

Finally, one way to improve the performance of the device, would be either to transform the nonstoichiometric a- $\mathrm{SiO}_{x} / \mathrm{Al}-\mathrm{O}-\mathrm{Si}^{*}$ into a stoichiometric and more stable a- $\mathrm{SiO}_{2} / \mathrm{Al}-\mathrm{O}-\mathrm{Si}$ which would bring more $\mathrm{Al}$ vacancies (capable of trapping negative charges) and interstitial oxygen negatively charged [58] or to promote the formation of a stoichiometric a- $\mathrm{SiO}_{2}$ [63][64] to the detriment of the aluminum silicate.

\section{Conclusion}

In this work, we begin by studying electron-beam irradiation on the c-Si/a- $\mathrm{AlO}_{x}$ interface. Firstly, we show that decreasing the acceleration voltage from 200 to $80 \mathrm{keV}$ (reducing simultaneously the electron dose from $2.67 \times 10^{7}$ é $/ \AA^{2}$ to $1.03 \times 10^{7}$ é/ $/ \AA^{2}$ ) during STEM-EELS experiment allows both to preserve the structure at the interface and to reduce $\mathrm{Al}$ metallic spreading. Besides, this $\mathrm{Al}$ metallic was even more reduced by modifying STEM-EELS scan orientation acquisition from y axis orientation ( $\perp$ scan to the interface) to $\mathrm{x}$ axis orientation $(/ /$ scan to the interface). Two hypothesis have been laid out concerning the origin of the metallic $\mathrm{Al}$ at the c-Si/a- $\mathrm{AlO}_{x}$ interface. One of the two hypothesis supported the fact that $\mathrm{Al}$ is formed by a radiolysis electron-beam process with $\mathrm{a}-\mathrm{AlO}_{x}$. The other one is more in favor of a manufacturing process dependency origin. In both case, our results show that this metallic $\mathrm{Al}$ is not stable since it can be spread over the stack by the STEM probe. Otherwise, it could be interesting to establish an experimental plan to test other microscope parameters in order to go further in the study of electron-beam related artifacts. 
Regarding the composition of the c-Si/a- $\mathrm{AlO}_{x}$ interface, an ultrathin a-SiO${ }_{x}$ layer was found, and above this ultrathin layer, an aluminum silicate layer was characterized. Due to the presence of a-SiO $\mathrm{S}_{x}$ and metallic $\mathrm{Al}$ site positively charged, the aluminum silicate is probably non-stoichiometric. At this interface, the negative charges improving the field effect passivation would therefore be mostly given by the tetrahedrally coordinated $\mathrm{Al}$ which has net negative charges. Finally, to bring more negative fixed charges, the aluminum silicate and/or the silicon oxide at the interface should be stoichiometric, which would bring more interstitial oxygen and $\mathrm{Al}$ vacancies known to be negatively charged.

To conclude, this article has shown that the characterization of unstable and non-stoichiometric materials as used in the photovoltaic field is not trivial. These characterizations could be improved using TEM techniques that are applied in biology filed such as e.g.: cryo-TEM, cryo-sample-holder or low dose camera [65].

\section{References}

[1] Raghaw S. Rai and Swaminathan Subramanian. "Role of Transmission Electron Microscopy in the Semiconductor Industry for Process Development and Failure Analysis". en. In: Progress in Crystal Growth and Characterization of Materials 55.3 (Sept. 2009), pp. 63-97. ISSN: 0960-8974. DOI: $10.1016 / j \cdot$ pcrysgrow. 2009.09.002.

[2] Jack Murray et al. "Electron Beam Induced Crystallization of Sputter Deposited Amorphous Alumina Thin Films". en. In: Materials Letters 74 (May 2012), pp. 12-15. ISSN: 0167-577X. DOI: 10.1016/j.matlet.2012.01.039.

[3] R. Nakamura et al. "Atomic Rearrangements in Amorphous $\mathrm{Al}_{2} \mathrm{O}_{3}$ under Electron-Beam Irradiation". en. In: Journal of Applied Physics 113.6 (Feb. 2013), p. 064312. ISSN: 0021-8979, 1089-7550. DOI: $10.1063 / 1.4790705$.

[4] Alberto Zobelli et al. "Spatial and Spectral Dynamics in STEM Hyperspectral Imaging Using Random Scan Patterns". en. In: Ultramicroscopy 212 (May 2020), p. 112912. ISSN: 0304-3991. DOI: $10.1016 / j \cdot u l t r a m i c .2019 .112912$. 
[5] Jonathan P. Mailoa et al. "A 2-Terminal Perovskite/Silicon Multijunction Solar Cell Enabled by a Silicon Tunnel Junction". In: Applied Physics Letters 106.12 (Mar. 2015), p. 121105. ISSN: 0003-6951. DOI: 10.1063/1.4914179.

[6] Jan Amaru Töfflinger et al. "PECVD-AlOx/SiNx Passivation Stacks on Wet Chemically Oxidized Silicon: Constant Voltage Stress Investigations of Charge Dynamics and Interface Defect States". English. In: Solar Energy Materials and Solar Cells Complete.135 (2015), pp. 49-56. ISSN: 09270248. DOI: $10.1016 / j$.solmat.2014.09.024.

[7] Gurleen Kaur et al. "Understanding Surface Treatment and ALD AlOx Thickness Induced Surface Passivation Quality of C-Si Cz Wafers". In: IEEE Journal of Photovoltaics 7.5 (Sept. 2017), pp. 1224-1235. ISSN: 2156-3381, 2156-3403. DOI: 10.1109/JPHOTOV.2017. 2717040.

[8] Oliver A. Dicks et al. "The Origin of Negative Charging in Amorphous Al2O3 Films: The Role of Native Defects". en. In: Nanotechnology 30.20 (Mar. 2019), p. 205201. ISSN: 0957-4484. DOI: 10.1088/1361-6528/ab0450.

[9] Fabien Lebreton et al. "Benefits of a Thermal Drift during Atomic Layer Deposition of Al2O3 for C-Si Passivation". In: 2017 IEEE 44th Photovoltaic Specialist Conference (PVSC). June 2017, pp. 1237-1240. DOI: 10.1109/PVSC. 2017.8366269.

[10] Armin G. Aberle. "Surface Passivation of Crystalline Silicon Solar Cells: A Review". en. In: Progress in Photovoltaics: Research and Applications 8.5 (2000), pp. 473-487. ISSN: 1099-159X. DOI: 10.1002/1099-159X (200009/10)8:5<473: : AID-PIP337>3.0.C0;2-D.

[11] Fabien Lebreton et al. "Blistering of Al2O3/a-SiNx:H Stacks: Analysis of the Submerged Part of the Iceberg by Colored Picosecond Acoustic Microscopy". In: 2017 IEEE 44th Photovoltaic Specialist Conference (PVSC). Washington, DC: IEEE, June 2017, pp. 464-466. ISBN: 978-15090-5605-7. DOI: 10.1109/PVSC. 2017.8366749.

[12] D. Lincot et al. "Study of One-Step Annealing for Plated Nickel-Copper Contacts on n-Pert Bifacial Monocrystalline Silicon Solar Cells". en. In: 32nd European Photovoltaic Solar Energy Conference and Exhibition (July 2016), pp. 697-702. DOI: 10.4229/EUPVSEC20162016-2AV.2.9. 
[13] Fabien Lebreton et al. "Deleterious Electrostatic Interaction in Silicon Passivation Stack between Thin ALD Al2O3 and Its A-SiNX:H Capping Layer: Numerical and Experimental Evidences". en. In: Energy Procedia. 7th International Conference on Silicon Photovoltaics, SiliconPV 2017, 3-5 April 2017, Freiburg, Germany 124 (Sept. 2017), pp. 91-98. ISSN: 1876-6102. DOI: 10.1016/ j.egypro.2017.09.328.

[14] Miroslava Schaffer, Bernhard Schaffer, and Quentin Ramasse. "Sample Preparation for AtomicResolution STEM at Low Voltages by FIB”. en. In: Ultramicroscopy 114 (Mar. 2012), pp. 62-71. ISSN: 03043991. DOI: 10.1016/j.ultramic.2012.01.005.

[15] Sara Bals et al. "High-Quality Sample Preparation by Low kV FIB Thinning for Analytical TEM Measurements". en. In: Microscopy and Microanalysis 13.02 (Apr. 2007), pp. 80-86. ISSN: 1431-9276, 1435-8115. DOI: 10.1017/S1431927607070018.

[16] Zhouguang Wang et al. "Surface Damage Induced by Focused-Ion-Beam Milling in a Si/Si p-n Junction Cross-Sectional Specimen". en. In: Applied Surface Science. The 9th International Symposium on Advanced Physical Fields 241.1 (Feb. 2005), pp. 80-86. ISSN: 0169-4332. DOI: $10.1016 / j$. apsusc. 2004.09 .092$.

[17] C. Jeanguillaume and C. Colliex. "Spectrum-Image: The next Step in EELS Digital Acquisition and Processing". en. In: Ultramicroscopy 28.1 (Apr. 1989), pp. 252-257. ISSN: 0304-3991. DOI: 10.1016/0304-3991 (89) 90304-5.

[18] R. D. Leapman and C. R. Swyt. "Separation of Overlapping Core Edges in Electron Energy Loss Spectra by Multiple-Least-Squares Fitting". eng. In: Ultramicroscopy 26.4 (1988), pp. 393-403. ISSN: 0304-3991. DOI: 10.1016/0304-3991 (88)90239-2.

[19] Chiennan Pan, Pouyan Shen, and Shuei-Yuan Chen. "Condensation, Crystallization and Coalescence of Amorphous Al2O3 Nanoparticles". en. In: Journal of Crystal Growth 299.2 (Feb. 2007), pp. 393-398. ISSN: 0022-0248. DOI: 10.1016/j.jcrysgro.2006.12.006.

[20] Binghai Liu et al. "Electron-Beam Radiation Induced Degradation of Silicon Nitride and Its Impact to Semiconductor Failure Analysis by TEM". In: AIP Advances 8.11 (Nov. 2018), p. 115327. DOI: $10.1063 / 1.5051813$. 
[21] Danièle Bouchet and Christian Colliex. "Experimental Study of ELNES at Grain Boundaries in Alumina: Intergranular Radiation Damage Effects on Al-L23 and O-K Edges". en. In: Ultramicroscopy 96.2 (Aug. 2003), pp. 139-152. ISSN: 03043991. DOI: 10.1016/S0304-3991 (02) 00437-0.

[22] K. Kimoto et al. "Coordination and Interface Analysis of Atomic-Layer-Deposition Al2O3 on Si(001) Using Energy-Loss near-Edge Structures". en. In: Applied Physics Letters 83.21 (Nov. 2003), pp. 4306-4308. ISSN: 0003-6951, 1077-3118. DOI: 10.1063/1.1629397.

[23] Bram Hoex et al. "Silicon Surface Passivation by Aluminium Oxide Studied with Electron Energy Loss Spectroscopy: Silicon Surface Passivation by Aluminium Oxide Studied with Electron Energy Loss Spectroscopy". en. In: physica status solidi (RRL) - Rapid Research Letters 7.11 (Nov. 2013), pp. 937-941. ISSN: 18626254. DOI: 10.1002/pssr.201308081.

[24] R. Dupree et al. "A MAS NMR STUDY OF THE STRUCTURE OF AMORPHOUS ALUMINA FILMS". en. In: Le Journal de Physique Colloques 46.C8 (Dec. 1985), pp. C8-113-C8-117. ISSN: 0449-1947. DOI: $10.1051 /$ jphyscol: 1985814.

[25] Sung Keun Lee et al. "Structure and Disorder in Amorphous Alumina Thin Films: Insights from High-Resolution Solid-State NMR". In: The Journal of Physical Chemistry C 114.32 (Aug. 2010), pp. 13890-13894. ISSN: 1932-7447. DOI: 10.1021/jp105306r.

[26] Vanessa Riffet. Statistics-Based Analysis of the Evolution of Structural and Electronic Properties of Realistic Amorphous Alumina During the Densification Process: Insights from First-Principles Approach / The Journal of Physical Chemistry C. https://pubs.acs.org/doi/abs/10.1021/acs.jpcc.7b06887. May 2019.

[27] Alain N. Gleizes et al. "Temperature Dependent 4-, 5- and 6-Fold Coordination of Aluminum in MOCVD-Grown Amorphous Alumina Films: From Local Coordination to Material Properties". In: Advances in Science and Technology 91 (Oct. 2014), pp. 123-133. ISSN: 1662-0356. DOI: 10.4028/www.scientific.net/AST.91.123.

[28] R.F. Egerton, P. Li, and M. Malac. "Radiation Damage in the TEM and SEM". en. In: Micron 35.6 (Aug. 2004), pp. 399-409. ISSN: 09684328. DOI: 10.1016/j.micron.2004.02.003. 
[29] L. W. Hobbs. "Radiation Effects in Analysis of Inorganic Specimens by TEM". en. In: Introduction to Analytical Electron Microscopy. Ed. by John J. Hren, Joseph I. Goldstein, and David C. Joy. Boston, MA: Springer US, 1979, pp. 437-480. ISBN: 978-1-4757-5583-1 978-1-4757-5581-7. DOI: $10.1007 / 978-1-4757-5581-7 \_17$.

[30] J. J. Loferski and P. Rappaport. "Radiation Damage in Ge and Si Detected by Carrier Lifetime Changes: Damage Thresholds". In: Physical Review 111.2 (July 1958), pp. 432-439. DOI: 10 . 1103/PhysRev.111.432.

[31] A. Yu. Konobeyev et al. "Evaluation of Effective Threshold Displacement Energies and Other Data Required for the Calculation of Advanced Atomic Displacement Cross-Sections". en. In: Nuclear Energy and Technology 3.3 (Sept. 2017), pp. 169-175. ISSN: 2452-3038. DOI: 10.1016/ j.nucet.2017.08.007.

[32] E. Holmström, A. Kuronen, and K. Nordlund. "Threshold Defect Production in Silicon Determined by Density Functional Theory Molecular Dynamics Simulations". In: Physical Review B 78.4 (July 2008), p. 045202. DOI: 10.1103/PhysRevB.78.045202.

[33] C. M. Wang et al. "Electron Beam-Induced Thickening of the Protective Oxide Layer around Fe Nanoparticles". eng. In: Ultramicroscopy 108.1 (Dec. 2007), pp. 43-51. ISSN: 0304-3991. DOI: 10.1016/j.ultramic.2007.03.002.

[34] S. J. Zinkle and C. Kinoshita. "Defect Production in Ceramics". en. In: Journal of Nuclear Materials. Proceedings of the International Workshop on Defect Production, Accumulation and Materials Performance in an Irradiation Environment 251 (Nov. 1997), pp. 200-217. ISSN: 00223115. DOI: $10.1016 / \mathrm{S} 0022-3115$ (97)00224-9.

[35] Carl J. McHargue. "Ion Beam Modification of Ceramics". en. In: Materials Science and Engineering: A 253.1-2 (Sept. 1998), pp. 94-105. ISSN: 09215093. DOI: 10.1016/S0921-5093(98) 00714-X.

[36] Elizabeth A. Cooper, Harriet Kung, and Michael Nastasi. "Systematic Study of the Ion Beam Mixing of Oxide Markers into Alumina". en. In: Nuclear Instruments and Methods in Physics Research Section B: Beam Interactions with Materials and Atoms 106.1-4 (Dec. 1995), pp. 9-16. ISSN: 0168583X. DOI: 10.1016/0168-583X (95) 00669-9. 
[37] R. F. Egerton. "Radiation Damage to Organic and Inorganic Specimens in the TEM". en. In: Micron 119 (Apr. 2019), pp. 72-87. ISSN: 0968-4328. DOI: 10.1016/j.micron.2019.01.005.

[38] R. Nakamura et al. "Nanovoid Formation through the Annealing of Amorphous Al2O3 and WO3 Films". en. In: Scripta Materialia 64.2 (Jan. 2011), pp. 197-200. ISSN: 1359-6462. DOI: 10.1016/j.scriptamat.2010.09.043.

[39] Y. Tomokiyo, T. Kuroiwa, and C. Kinoshita. "Defects Occurring at or near Surfaces in $\alpha$-Al2O3 during Electron Irradiation”. en. In: Ultramicroscopy 39.1 (Nov. 1991), pp. 213-221. ISSN: 03043991. DOI: $10.1016 / 0304-3991$ (91) 90200-P.

[40] G. P. Pells and D. C. Phillips. "Radiation Damage of $\alpha$-Al2O3 in the HVEM: II. Radiation Damage at High Temperature and High Dose". en. In: Journal of Nuclear Materials 80.2 (May 1979), pp. 215-222. ISSN: 0022-3115. DOI: 10.1016/0022-3115(79)90184-3.

[41] John E. Bonevich and Laurence D. Marks. "Electron Radiation Damage of $\alpha$-Alumina". en. In: Ultramicroscopy 35.2 (Feb. 1991), pp. 161-166. ISSN: 0304-3991. DOI: 10.1016/0304-3991(91) 90101-B.

[42] S. D. Berger et al. "Electron Energy-Loss Spectroscopy Studies of Nanometre-Scale Structures in Alumina Produced by Intense Electron-Beam Irradiation”. en. In: Philosophical Magazine B 55.3 (Mar. 1987), pp. 341-358. ISSN: 1364-2812, 1463-6417. DOI: 10.1080/13642818708208619.

[43] Lunjie Zeng et al. "Atomic Structure and Oxygen Deficiency of the Ultrathin Aluminium Oxide Barrier in $\mathrm{Al} / \mathrm{AlOx} / \mathrm{Al}$ Josephson Junctions". en. In: Scientific Reports 6.1 (Sept. 2016). ISSN: 2045-2322. DOI: $10.1038 /$ srep29679.

[44] S. Fritz et al. "Correlating the Nanostructure of Al-Oxide with Deposition Conditions and Dielectric Contributions of Two-Level Systems in Perspective of Superconducting Quantum Circuits". en. In: Scientific Reports 8.1 (May 2018), pp. 1-11. ISSN: 2045-2322. DOI: 10.1038/s41598-01826066-4.

[45] Vincent Sarou-Kanian et al. "Temperature-Dependent 4-, 5- and 6-Fold Coordination of Aluminum in MOCVD-Grown Amorphous Alumina Films: A Very High Field 27Al-NMR Study". 
In: The Journal of Physical Chemistry C 117.42 (Oct. 2013), pp. 21965-21971. ISSN: 1932-7447. DOI: $10.1021 / j p 4077504$.

[46] M. L. Knotek and Peter J. Feibelman. "Ion Desorption by Core-Hole Auger Decay". In: Physical Review Letters 40.14 (Apr. 1978), pp. 964-967. DOI: 10.1103/PhysRevLett.40.964.

[47] A. Meldrum, L. A. Boatner, and R. C. Ewing. "Electron-Irradiation-Induced Nucleation and Growth in Amorphous LaPO4, ScPO4, and Zircon". en. In: Journal of Materials Research 12.7 (July 1997), pp. 1816-1827. ISSN: 2044-5326, 0884-2914. DOI: 10.1557/JMR.1997.0250.

[48] D. G. Howitt et al. "The Electron Beam Hole Drilling of Silicon Nitride Thin Films". In: Journal of Applied Physics 103.2 (Jan. 2008), p. 024310. ISSN: 0021-8979. DOI: 10.1063/1.2828157.

[49] P. E. Batson. "Simultaneous STEM Imaging and Electron Energy-Loss Spectroscopy with AtomicColumn Sensitivity”. En. In: Nature 366.6457 (Dec. 1993), p. 727. ISSN: 1476-4687. DOI: 10.1038/ $366727 \mathrm{a} 0$.

[50] Anna Kimmel et al. "Positive and Negative Oxygen Vacancies in Amorphous Silica". en. In: ECS Transactions 19.2 (May 2009), p. 3. ISSN: 1938-5862. DOI: 10.1149/1.3122083.

[51] F. J. Himpsel et al. "Microscopic Structure of the SiO 2 /Si Interface". en. In: Physical Review B 38.9 (Sept. 1988), pp. 6084-6096. ISSN: 0163-1829. DOI: 10.1103/PhysRevB.38.6084.

[52] C. F. George and P. D'Antonio. "An Electron Diffraction Study of Amorphous Silicon Oxide Films". en. In: Journal of Non-Crystalline Solids 34.3 (Dec. 1979), pp. 323-334. ISSN: 0022-3093. DOI: $10.1016 / 0022-3093(79) 90019-X$.

[53] E. Martínez and F. Ynduráin. "ELECTRONIC STRUCTURE OF AMORPHOUS SiOx". In: Journal de Physique Colloques 42.C4 (1981), pp. C4-1021-C4-1024. DOI: 10.1051/jphyscol: 19814223.

[54] Yu N. Novikov and V. A. Gritsenko. "Short-Range Order in Amorphous SiOx by x Ray Photoelectron Spectroscopy". en. In: Journal of Applied Physics 110.1 (July 2011), p. 014107. ISSN: 0021-8979. DOI: $10.1063 / 1.3606422$. 
[55] Maxence Valla et al. "Atomic Description of the Interface between Silica and Alumina in Aluminosilicates through Dynamic Nuclear Polarization Surface-Enhanced NMR Spectroscopy and First-Principles Calculations". In: Journal of the American Chemical Society 137.33 (Aug. 2015), pp. 10710-10719. ISSN: 0002-7863. DOI: 10.1021/jacs.5b06134.

[56] Mohau Moshoeshoe, Misael Silas Nadiye-Tabbiruka, and Veronica Obuseng. "A Review of the Chemistry, Structure, Properties and Applications of Zeolites". en. In: American Journal of Materials Science 7.5 (/26/2017), pp. 196-221. ISSN: 2162-8424.

[57] Robert S. Johnson, Gerald Lucovsky, and Isreal Baumvol. "Physical and Electrical Properties of Noncrystalline A12O3 Prepared by Remote Plasma Enhanced Chemical Vapor Deposition". In: Journal of Vacuum Science 83 Technology A 19.4 (July 2001), pp. 1353-1360. ISSN: 0734-2101. DOI: $10.1116 / 1.1379316$.

[58] M.-H. Cho et al. "Annealing Effects of Aluminum Silicate Films Grown on Si(100)". In: Journal of Vacuum Science $\& 3$ Technology A 20.3 (May 2002), pp. 865-872. ISSN: 0734-2101. DOI: 10. $1116 / 1.1472422$.

[59] Katsuyuki Matsunaga et al. "First-Principles Calculations of Intrinsic Defects in $\$\{\backslash \text { mathrm }\{\mathrm{Al}\}\}_{-}\{2\}\{\backslash \operatorname{mathrm}\{\mathrm{O}\}$ In: Physical Review B 68.8 (Aug. 2003), p. 085110. DOI: 10.1103/PhysRevB.68.085110.

[60] Fabien Lebreton. "Silicon Surface Passivation Properties of Aluminum Oxide Grown by Atomic Layer Deposition for Low Temperature Solar Cells Processes". en. PhD thesis. Université ParisSaclay, Dec. 2017.

[61] Maxime Caillot et al. "The Variety of Brønsted Acid Sites in Amorphous Aluminosilicates and Zeolites". en. In: Journal of Catalysis 316 (July 2014), pp. 47-56. ISSN: 0021-9517. DOI: 10.1016/ j.jcat.2014.05.002.

[62] Bin Xu et al. "Strong Brønsted Acidity in Amorphous Silica-Aluminas". In: The Journal of Physical Chemistry C 111.32 (Aug. 2007), pp. 12075-12079. ISSN: 1932-7447. DOI: $10.1021 /$ jp073677i. 
[63] V. Naumann et al. "Interface and Material Characterization of Thin ALD-Al2O3 Layers on Crystalline Silicon". en. In: Energy Procedia 27 (2012), pp. 312-318. ISSN: 18766102. DOI: 10. 1016/j .egypro.2012.07.069.

[64] Saskia Kühnhold et al. "High-Temperature Degradation in Plasma-Enhanced Chemical Vapor Deposition $\mathrm{Al}_{2} \mathrm{O}_{3}$ Surface Passivation Layers on Crystalline Silicon”. en. In: Journal of Applied Physics 116.5 (Aug. 2014), p. 054507. ISSN: 0021-8979, 1089-7550. DOI: 10.1063/1.4891634.

[65] Łukasz Mielańczyk, Natalia Matysiak, and Olesya Klymenko and Romuald Wojnicz. "Transmission Electron Microscopy of Biological Samples". en. In: The Transmission Electron Microscope - Theory and Applications (Sept. 2015). DOI: 10.5772/60680. 